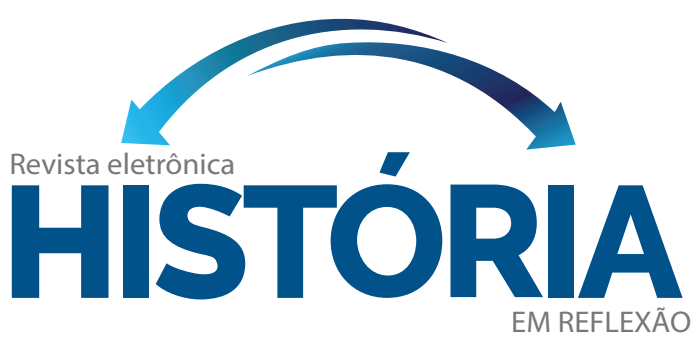

PPGH - Programa de Pós-Graduação em História UFGD - Universidade Federal da Grande Dourados

ISSN: 1981-2434

Dourados - MS - Brasil

\title{
MINERVA BRASILIENSE: CIVILIZACCÃO, PROGRESSO E SEU PROJETO ILUSTRATIVO
}

\section{MINERVA BRASILIENSE: CIVILIZATION, PROGRESS AND ITS ILLUSTRATIVE PROJECT}

\author{
BRUNA SCHULTE MOURA*
}

\begin{abstract}
RESUMO
O artigo tem como objetivo balizar os caminhos do projeto de nação que estava sendo discutido pela elite imperial, no qual o periódico Minerva Brasiliense se colocou como um importante espaço de discussão desta problemática. Além disso, creio ser importante realizar um balanço sobre como se deu este projeto a partir da compreensão da aplicação de conceitos historicizados na revista. Nesse sentido, é importante localizar que o estudo da prática historiográfica se apresenta como um importante meio de diálogo para compreender a mentalidade passada e conhecer os efeitos dela no presente.
\end{abstract}

PALAVRAS-CHAVE: Historiografia. História dos conceitos. Projeto ilustrativo.

\begin{abstract}
The article aims to outline the ways that the nation project that was being discussed by the imperial elite was designed, and how the journal Minerva Brasiliense poses as an important space for discussion of this problem. In addition, I think it is important to take stock of how this project came from understanding the application of historicized concepts in the journal. In this sense, it is important to locate that the study of historiographic practice presents itself as an important means of dialogue to understand the past mentality and to know the effects of it in the present.
\end{abstract}

KEY WORDS: Historiography. History of concepts. Illustrative project.

\footnotetext{
* Mestre em História Política e Cultural pela UERJ financiada pela FAPERJ, Doutoranda do Programa de Pós-graduação em História da UNICAMP na linha de Política, Cultura e Memória. Bolsista CNPq. E-mail: schulte.bruna@gmail.com.
} 
Em primeiro de novembro de 1843 veio à luz o primeiro número de um importante periódico que tinha como missão um projeto pedagógico ilustrativo bastante elaborado e alinhado com o momento político em questão. Buscando preencher uma lacuna intelectual na imprensa periódica, os redatores de Minerva Brasiliense deram início à uma empreitada científica e literária que tinha como objetivo oferecer meios para o desenvolvimento das inteligências no Brasil recém-independente. Em seu prospecto, publicado no Diário do Rio de Janeiro, no número duzentos e catorze, do dia vinte e seis de setembro de 1843, ou seja, pouco mais de um mês da publicação de seu primeiro número, os redatores do periódico antecipam brevemente os objetivos de sua missão com o novo impresso na cena ilustrada fluminense.

Os autores localizaram o lugar da imprensa da corte, onde afirmavam que basicamente ocupava-se dos assuntos de política e comércio, mas pouco se desenvolvia sobre ciências, literatura e artes, assuntos estes os quais esses homens pretendem potencializar. Os homens que tinham como objetivo "promover a cultura intelectual da nossa população”, escreveram no prospecto já mencionado:

\begin{abstract}
É uma imensa lacuna que não pode ser olhada com indiferença no meio dos progressos de toda a sorte que o Brasil tem feito nos caminhos da civilização, e é a falta de publicações periódicas consagradas às letras, às ciências e às artes, que, servindo de vínculo aos trabalhos já feitos neste país, transmita e defenda conjuntamente com eles a notícia do que de mais notável e importante oferecem as nações civilizadas nos diversos ramos de conhecimentos humanos (Diário do Rio de Janeiro, n. 214, p. 2).
\end{abstract}

Carregados dos conceitos de civilização e progresso - já observáveis neste prospecto -, os literatos que fizeram parte deste projeto iniciaram então este empreendimento dedicado ao desenvolvimento das letras e ciências no Brasil a partir do que consideraram como lacuna. Neste pequeno texto publicado no Diário do Rio de Janeiro já se apresenta a possibilidade de identificar alguns dos objetivos com os quais os literatos envolvidos se comprometeram, como podemos observar no trecho a seguir:

As vantagens que em toda parte tem colhido das publicações da natureza de que tratamos, e que cada dia se vai consideravelmente se multiplicando, são tão obvias e palpáveis, que quase ocioso fora o enuncia-las aqui. Elas proporcionam a todas as classes um meio pronto, cômodo e fácil de instrução, removendo as dificuldades que alias encontram-se para construir este fim; aos homens de profissões ativas e laboriosas, a quem falta o tempo, o repouso e a fortuna para o estudo aturado, oferecem em alguns capítulos sucintos e substanciais um cabedal variado de conhecimento, que de outra sorte só encontrarão em longos e numerosos volumes: propagam a gosto de leitura, vulgarizando a ciência, travestindo-a de formas singelas e populares e pondo-a no alcance de todas as capacidades, estendem os seus benefícios até os últimos graus da escala social, e contribuem assim para a verdadeira emancipação do homem com o libertá-lo do jugo do erro e da ignorância; finalmente nas épocas críticas das sociedades elas podem operar uma salutar transformação na desordem dos espíritos, fixando as ideias sobre as grandes verdades morais, religiosas e políticas, e destarte preparam um futuro melhor (Diário do Rio de Janeiro, n. 214, p. 2).

Ainda nesta pequena apresentação, os autores a definem como uma "uma 
reunião de literatos nacionais e estrangeiros" que buscará atingir "todas as inteligências, e quer nas ciências e quer nas letras e nas artes", não se ocupando de assuntos de política a não ser que sejam "tratados sob um ponto de vista genérico e meramente especulativo" (Diário do Rio de Janeiro, n. 214, p. 2). O trecho demonstra que há uma latente proposta ilustrativa por parte dos redatores de Minerva, que claramente se dirigem a um público leitor bastante específico: seus pares.

A fim de se compreender de forma mais profunda a Revista científica e literária Minerva Brasiliense, ressalta-se a relevância de conhecer projeto ilustrativo ao qual a revista se incumbe. Neste sentido é importante salientar que uma das questões chave de desenvolvimento deste debate centra-se na percepção de para quem os editores desta revista se dirigem, qual seu público alvo? A partir desta questão é possível apreender a forma como o projeto de ilustração funcionou para formular uma ideia de história do Brasil, assim como ajuda a ter uma percepção mais clara sobre a elite do Império no começo da década de 1840.

Desta forma, apresentar-se-á uma análise dos textos "Progressos do século atual", publicado como introdução do primeiro número de Minerva do ano de 1843 e escrito por seu então redator chefe Francisco de Salles Torres Homem, e "Grandes fases da civilização brasileira: antecedentes e caráter dos progressos literários e sociais: jornalismo: novas vistas da Minerva, etc", também publicado como introdução, mas da nova fase da revista com Santiago Nunes Ribeiro à frente da empreitada, no segundo número um datado de 1844. Estes textos também apresentam algumas compreensões de seus escritores que torna possível entender os objetivos deste periódico.

\section{O Perfil de letrados que atuaram em Minerva Brasiliense}

Com a finalidade de compreender melhor o objetivo do periódico aqui analisado, apresenta-se a necessidade de conhecer mais profundamente o corpo de colaboradores da referida revista. Utilizo-me do recurso de um trabalho já realizado por Tânia Maria Tavares Bessone da Cruz Ferreira, em colaboração ao livro "Minerva Brasiliense: leituras", organizado pelas professoras Lúcia Maria Bastos Pereira das Neves e Lúcia Maria Paschoal Guimarães, que desvela as variadas frentes do periódico aqui tratado. Tânia T. B. da C. Ferreira, particularmente, realiza um trabalho prosopográfico que, através de dados das vidas dos colaboradores mais assíduos, constrói uma resumida biografia de cada um deles.

De acordo com os dados apresentados por Ferreira, podemos notar que do universo de quarenta e um colaboradores, trinta e dois deles - aproximadamente setenta e oito por cento - eram sócios do Instituto Histórico e Geográfico Brasileiro e quinze - cerca de trinta e seis por cento - eram professores do Colégio Pedro II. Estas foram as duas categorias destacadas pela professora e, deste total, dezoito deles - em torno de quarenta e quatro por cento - eram apenas sócios do IHGB e um 
destes colaboradores eram somente professor do Colégio Pedro II, sem associação ao IHGB. Catorze destes homens colaboravam com ambas as instituições - por volta de trinta e quatro por cento - e oito deles não atuavam em nenhuma delas - em torno de vinte por cento (NEVES; GUIMARÃES, 2016, p. 47-51).

Além disso, na breve apresentação das atividades destes letrados, podemos destacar outras funções que estes homens desempenharam. Além da grande maioria destes ocuparem cargos na alta cúpula intelectual do Império (como por exemplo, diretores do Museu Nacional, Jardim Botânico, Passeio Público, Arquivo Nacional, Biblioteca Nacional, Academia Militar, Escola Militar, Faculdade de Medicina, Escola Central do Exército, Imperial Observatório do Rio de Janeiro, presidentes de províncias, presidentes do Banco do Brasil, senadores, deputados, conselheiros do imperador, secretários de governo, professores universitários, médicos em importantes hospitais, entre outros), podemos ainda observar algumas atividades próximas entre eles, que também refletem nos objetivos do periódico aqui estudado.

Para além dos professores que atuaram no Colégio Pedro II, temos quatro professores de instituições militares, quatro professores universitários, três conselheiros do Império, treze letrados que atuaram também na política (senadores, secretários, deputados, presidentes de províncias, etc.) e cinco membros das atividades científicas do Museu Nacional. Ainda pode ser destacado que quatro destes letrados foram membros em legações brasileiras no exterior, quatro presidentes de províncias, cinco ministros do Império, nove deputados e seis senadores.

A formação acadêmica dos homens que colaboravam com a publicação em questão também tem muito a contribuir na apreensão de seu corpo editorial. De acordo com Ferreira, um letrado tinha formação em Belas Letras, dois em filosofia, dois em Belas Artes, três em ciências naturais, três em ciências matemáticas, oito em direito e catorze em medicina. Alguns deles acumulavam mais de uma formação, como é o caso de Cândido de Azeredo Coutinho, formado em Matemática e na Escola Militar, Emílio Joaquim da Silva Maia, formado em filosofia pela Universidade de Coimbra, ciências físicas e matemáticas e medicina pela Universidade de Paris, Joaquim Cândido Guillobel, formado pela Escola Militar e pela Academia Imperial de Belas Artes, Joaquim Vicente Torres Homem, com formação em Ciências Físicas e Naturais e medicina em Paris, Joaquim Martins da Cruz Jobim, formado em Ciências Naturais e Medicina também em Paris, Pedro de Alcântara Bellegarde, que estudou ciências matemáticas e engenharia na Academia Militar do Rio de Janeiro e Francisco de Salles Torres Homem, com formação em medicina e direito em Paris. Outros letrados também se dedicavam a vida religiosa, como o caso de Januário da Cunha Barbosa, Manuel Joaquim da Silveira e Camilo Cléau (ou Frei Camilo de Montserrate) (NEVES; GUIMARÃES, 2016, p. 47-51).

Ainda sobre a formação destes homens, de acordo com Ferreira, podemos ressaltar que um formou-se pela universidade de Kiel, na Alemanha, nove se formaram no Brasil, um em Gênova, na Itália, nove em Paris e sete em Coimbra. Dos que se formaram no Brasil, seis frequentaram a Faculdade do Rio de Janeiro, dois a Escola Militar, um a Faculdade da Bahia, um a Academia Militar, um a Universidade de São 
Paulo e um a Academia Imperial de Belas Artes.

Dentre os colaboradores destacados, Domingos Gonçalves de Magalhães tem como uma das principais funções destacadas a de escritor, juntamente com José Manuel Valdez y Palacios e Antônio Gonçalves Teixeira e Sousa. Francisco de Salles Torres Homem, José Manuel Valdez y Palacios e Carlos Emílio Adet têm ressaltadas suas atividades como publicistas. Santiago Nunes Ribeiro tem como principais atividades desempenhadas ao longo de sua vida as de crítico literário e poeta. Antônio Francisco Dutra e Melo é ressaltado como poeta romântico enquanto Joaquim Manuel de Macedo tem sua atividade de romancista destacada. Dois magistrados também colaboraram com a revista, Manuel Alves Branco e Rodrigo de Sousa da Silva Pontes.1

Estas informações se fazem pertinentes no sentido de compreender quem são e em quais esferas no universo intelectual, político e social estão os redatores que publicaram artigos, estudos, resultados de pesquisa, ensaios, entre outros, na referida revista. Percebemos uma grande quantidade de colaboradores formados em Paris, o que nos possibilita pensar sobre a influência deste país no esforço de construir uma civilização à francesa no Brasil e se torna bastante sintomático neste cenário. Outro ponto a ser destacado é a experiência que grande parte destes homens tiveram na Europa, na sua formação, e como este influxo está presente no projeto ilustrativo que é fio condutor desta publicação.

Mais um ponto relevante que merece destaque é a quantidade de contribuintes de Minerva que tem formação em ciências exatas e da natureza, assim como médicos, em detrimento daqueles com formação nas áreas humanas e das letras, que também demonstra uma preocupação mais científica que literária, uma vez que a área das ciências aparentemente obtinha maior prestígio e exigência de formação. Por fim, destaco que ter conhecimento de quem são, qual formação, quais as áreas de atuação e qual é a classe social à qual estes homens pertenciam nos oferece um panorama na apreensão do público leitor alvo - que veremos adiante - pois oferece substrato suficiente na compreensão de quem eram seus pares.

\section{O Público alvo de Minerva Brasiliense}

A fim de se compreender para quem os redatores de Minerva falavam é importante levantar o desenvolvimento do conceito de povo durante o século XIX. Neste período especificamente não se pode perder de vista a ideia de cidadania, já que o vocábulo povo se articula diretamente com a ideia de cidadania. Luisa Rauter Pereira, que colaborou no livro sobre o léxico dos conceitos políticos no Brasil, destaca que durante o século XVIII, "povo" no Brasil se referia aos homens brancos proprietários de terra e também aos homens de negócio, ou seja, aqueles capazes

1 Todas as informações aqui tratadas foram extraídas do capítulo "Minerva Brasiliense: redatores, colaboradores, publicistas", escrito por Tania Maria Tavares Bessone da Cruz Ferreira, presente no livro "Minerva Brasiliense leituras", entre as páginas 39 e 64 deste livro. 
de exercer a cidadania. Ao longo da passagem do século XVIII para o XIX, com as conjurações baiana, mineira e fluminense - no final do século XVIII -, transferência da capital metropolitana de Lisboa para o Rio de Janeiro, Revolução de 1820 em Portugal e a independência do Brasil, o conceito de "povo" se altera (JUNIOR, 2014, p. 174-178).

De acordo com a autora, o pacto entre povo e rei se renovaria a partir de 1820, deixando de ser uma relação de suserania e vassalagem e passando a ter uma conotação de pacto, enquanto a soberania se encontraria na constituição e o povo seria cidadão. Os debates a partir de 1822 no Brasil se caracterizam na definição e construção do conceito de povo-nação, ainda indefinido no começo desta década. "Povo" passa a ser, a partir da independência, uma identidade cultural e social coletiva, não cabendo apenas na ideia de onde se mora ou nasceu (JUNIOR, 2014, p. 178180).

Nos debates constitucionais de 1823, de acordo com Pereira, os dois grupos mais marcantes - dos federalistas e dos centralizadores - tinham duas visões distintas acerca do conceito aqui discutido: de um lado, os que defendiam a liberdade política (federalista) acreditavam que além de ser um direito, era também uma forma de aprimorar, constituir e formar o povo; no outro lado tinham aqueles que, mergulhados na identificação deste com a plebe, acreditavam ser intelectualmente incapazes, devendo portanto ser tutelados pela elite carioca (JUNIOR, 2014, p. 181).

A referida autora chama atenção para o fato de que entre o período de tempo analisado, há o surgimento da noção de povo-cidadão, mas que a ideia de povo como se compreendia no antigo regime ainda se manteve presente, mesmo depois dos câmbios ocorridos durante um século. Neste sentido, pode-se destacar que se compreendia, na linguagem política corrente, o lugar do povo como soberano político e sua distinção à plebe, marcando este vocábulo durante o século tratado (JUNIOR, 2014, p. 186).

A concepção de povo muito se diferia da concepção de cidadão, que hoje compreendemos quase como sinônimos. Na realidade do Antigo Regime luso brasileiro do século XVIII, a ideia de cidadania estava intimamente ligada à noção de "homem bom", associado a algum tipo de fidalguia. De acordo com Beatriz Catão Cruz Santos e Bernardo Ferreira, que se dedicam a analisar a concepção de cidadania entre os séculos XVIII e XIX no livro sobre o léxico dos conceitos políticos no Brasil, o vocábulo sofreu uma transformação profunda a partir da independência do Brasil. Segundo os autores, cidadania deixou de ter uma compreensão hierárquica e passou a ter uma significação mais igualitária (JUNIOR, 2014, p. 41-42).

Os autores afirmam, na história deste conceito, que o cidadão na sociedade do século XVIII colonial brasileiro se distinguia dos demais por ocupar uma posição superior. Cidadania não era sinônimo de nobreza, mas se aproximava dela, já que estes homens estavam habilitados socialmente a desempenharem funções administrativas locais. A partir dos movimentos de objeção do sistema colonial, no final do século XVIII, inicia-se um movimento de contestação desta compreensão hierárquica e estamental 
do vocábulo. Estas conjurações se caracterizam por demonstrar uma relativa perda de identificação com a coroa, buscando transferir a legitimidade do poder do trono para a população (JUNIOR, 2014, p. 43-47).

Podemos observar, no entanto, que durante os debates constitucionais da década de 1820 a cidadania foi um ponto de intensa discussão, sobretudo na definição do ser brasileiro. Muitas questões haviam para se decidirem acerca desta temática: os portugueses que viviam na colônia americana, deveriam fazer parte deste processo de tornar-se cidadão brasileiro? Os indígenas nativos eram cidadãos? Os negros africanos libertos deveriam ser colocados como parte desta sociedade? Neste sentido, é possível perceber que raça e cidadania, de acordo com os autores, interrelacionam-se como noções no continente americano, uma vez que é a partir da raça ou da cor da pele que a cidadania é instituída neste primeiro momento constitucional brasileiro, excluindo os negros escravizados deste processo (JUNIOR, 2014, p. 4850).

Sob o caráter censitário este problema acaba parcialmente resolvido já que, para desempenhar as funções de um cidadão era necessário ser proprietário de terras. Sendo assim, criam-se duas modalidades de cidadania, que se diferenciava a partir do critério referido: cidadãos ativos e cidadãos passivos. Segundo Santos e Ferreira, cidadania, liberdade e propriedade se relacionam na constituição do exercício da primeira, ou seja, livres e proprietários desempenhariam as funções de uma cidadania ativa, livres e não proprietários seriam os cidadãos passivos, enquanto os não livres e não proprietários não teriam acesso à cidadania (JUNIOR, 2014, p. 44-55).

Podemos perceber que, embora este conceito tenha sido discutido e redimensionado de forma a não ser mais caracterizado de forma hierárquica, a nova determinação não altera profundamente o exercício da cidadania. Apreendemos, portanto, que as noções de povo e cidadania no cenário político e social do Império brasileiro oitocentista tem forte caráter elitista. Esta concepção é imprescindível na busca acerca da percepção de um público leitor pré-determinado como o de Minerva Brasiliense.

\section{Francisco de Sales Torres Homem à frente de Minerva Brasiliense: marcha indefinida rumo à civilização e ao progresso}

Durante o primeiro ano em que Minerva Brasiliense foi publicada, quem esteve à frente do projeto foi o futuro Visconde de Inhomirim. Seu período de direção durou exatamente um ano, dirigindo do número um datado de primeiro de novembro de 1843 até o número vinte e quatro de quinze de outubro 1844, quando se retirou do projeto para retornar à vida política. Como redator-chefe da revista, Torres Homem publicou o artigo-introdução chamado "Progressos do século atual", que de acordo com Hélio Lopes, vale como artigo-manifesto da publicação, Torres Homem inicia o texto afirmando que "desde o princípio do século tem havido [progressos] nos 
diversos ramos da árvore enciclopédica, e em algum dos melhoramentos práticos da condição humana" (Minerva Brasiliense, n. 1, vol. 1, 1843, p. I). Posteriormente descreve os avanços ocorridos em diversas áreas do saber humano nas primeiras décadas do século XIX. História natural, medicina, química, física, política, moral, filosofia, psicologia, letras e o cristianismo, são citadas para realizar um balanço do aperfeiçoamento de todos os setores do saber.

Alguns exemplos ilustram tais ideias, como quando Torres Homem escreve que sobre os métodos científicos de investigação afirmando que foram substituídos por "Métodos severos de investigação" ao invés de "devaneios da imaginação na ciência médica" (Minerva Brasiliense, n. 1, vol. 1, 1843, p. I). Sobre as ciências políticas e morais o autor defende que "o sistema constitucional, que antes não passava de um grande fato estabelecido pela mão do tempo na Inglaterra, tornou-se um princípio, a fórmula da liberdade, a condição do progresso dos povos, o centro de sua política gravitação.", no qual o autor apresenta uma crença na constituição como soberana, em detrimento da soberania do trono, como já observamos nas transformações semânticas que ocorreram durante este período (Minerva Brasiliense, n. 1, vol. 1, 1843, p. III).

Sobre economia, Torres Homem avalia "Foi por terra a teoria da balança do comércio; e com ela parte dos obstáculos postos nas fronteiras, e no interior dos Estados à circulação dos produtos, que se busca hoje favorecer. ", dando a ideia de crença no liberalismo e superação do antigo modelo mercantilista da economia lusa (Minerva Brasiliense, n. 1, vol. 1, 1843, p. IV). Por fim, em conclusão a estes avanços, o autor declara, apresentando também sua crença no progresso:

\begin{abstract}
A vista destas tendências e de tantas empresas concebidas em menos de quarenta anos, cuja enumeração brevíssima acabamos de fazer, e quando o movimento intelectual continua em aceleração progressiva, é impossível não invejarmos a sorte das gerações futuras, destinadas a colher o fruto de tão grandes e úteis trabalhos!

$(\ldots)$

O homem continuará em sua marcha indefinida derrubando as barreiras que se Ihe apõe em cada século; o caminho que tem a percorrer, é imenso. Somente a sua missão no porvir será talvez mais tranquila, o parto da inteligência e da civilização menos laborioso, do que até aqui o tem sido, e o será ainda por algum tempo mais. (Minerva Brasiliense, n. 1, vol. 1, 1843, p. VI)
\end{abstract}

Ao fim de seu texto, o autor faz um rápido balanço das transições ocorridas no mundo ocidental. Inicialmente trata do século $\mathrm{V}$, quando o mundo romano desmorona, depois no século XV e sua luta contra a feudalidade, evoca o século XVI e a expansão do elemento religioso e, por fim, no século XIX, o desenvolvimento da indústria. Em conclusão, Torres Homem declara:

Parece que na ordem providencial do mundo, nada se obtém sem sacrifício; ele é a condição de nossa perfectibilidade; para que tenha lugar o progresso da sociedade é mister que uma geração seja oferecida em holocausto à outra. (Minerva Brasiliense, n. 1, vol. 1, 1843, p. VI) 
Apresentando seu nobre interesse de que não haja nenhum "holocausto" na transição que o Brasil vive, observa-se que ele reconhece e proclama para a sua geração a incumbência de trabalhar para a geração futura: "Para nós, portanto, os tormentos de uma época crítica, a fadiga da construção, os ardores da luta: para as gerações vindouras, as flores da primavera, o orvalho do céu, a fruição não disputada de sua herança." (Minerva Brasiliense, n. 1, vol. 1, 1843, p. VI) Percebe-se aqui as similaridades de pensamento que os aproximam em relação ao seu pretenso público leitor, pois quando observamos que o "nós" a quem o autor proclama a tal "fadiga da construção" pode ser identificada como sua própria geração de literatos, que dirigiam política e culturalmente o país recém-independente. Quando ele proclama para as "gerações vindouras" que colheriam "as flores da primavera", podemos compreender que estas pessoas são identificadas como seus discípulos, um público pensante, pertencente ao mesmo meio literário-político-científico que ele e seus colegas de redação. O que concluímos é que na verdade ele está se dirigindo aos seus pares pertencentes as classes mais altas da corte do Império Brasileiro. De acordo com Hélio Lopes:

Torres Homem toma consciência, e quer despertá-la em seus compatriotas, da responsabilidade de tudo fazerem, quanto Ihes compete, para facilitar o caminho dos vindouros. Reconhece e proclama para sua geração a incumbência de trabalhar para a geração futura. (LOPES, Hélio, 1978, p. 33)

O que podemos observar é que o autor resume os desejos pelos quais estes homens, pertencentes a esta geração, eram movidos: a ânsia de alcançar um progresso para tornar a nova nação firme culturalmente e colocá-la à altura dos povos mais antigos e adiantados. Além disso, proclama a sua geração como promovedora da transição necessária, ou seja, seriam eles os responsáveis pela construção da brasilidade, os românticos.

\section{Minerva Brasiliense sob a direção de Santiago Nunes Ribeiro e suas mudanças}

A partir de quinze de novembro de 1844, Torres Homem deixa a função de editor-chefe e esta passa para Santiago Nunes Ribeiro. Os números da revista recomeçam e a publicação da referida data tem novamente o número um. A tipografia também muda, saindo da J. E. S. Cabral, na Rua do Hospício número seis e passando para a Tipografia Austral, no Beco de Bragança, número quinze, o que não altera em nada os volumes, apenas reinicia a contagem dos números.

No seu artigo "Grandes fases da civilização brasileira: antecedentes e caráter dos progressos literários e sociais: jornalismo: novas vistas da Minerva, etc", Nunes Ribeiro estampa a introdução desta nova fase de Minerva com suas propostas. Inicialmente, o autor faz um retrospecto das inovações ocorridas no século XV, falando sobre Guttemberg, Lutero, Vasco da Gama e Colombo. Fala-se também acerca das conquistas na América, enaltecendo Pedro Álvares Cabral, em uma suposição do que aconteceria se Colombo não tivesse sido atendido pelos reis da Espanha. Ribeiro

Revista História em Reflexão, Vol. 15, N. 29 | jan. a jun. de 2021 
também faz considerações positivas da administração colonial de Portugal ao Brasil de 1500 a 1822. Nota-se que este autor, em relação ao redator-chefe anterior, desenvolve uma linha de raciocínio voltada para a questão do desenvolvimento americano em detrimento do progresso civilizatório europeu. (Minerva Brasiliense, n. 1, vol. III, 1844, p. 1)

A partir deste momento, o artigo apresenta um breve resumo sobre a história brasileira, abarcando, sobretudo a vinda da família real, a decisão da permanência de D. Pedro I e o processo de declínio da monarquia portuguesa. Traça, a partir daí, um paralelo com os movimentos ocorridos no Brasil afirmando: "No Brasil, quase nos mesmos dias, se opera uma resolução, a passagem deste país da infância a adolescência, à emancipação política: esforço algum pode impedi-la, porque Deus dissera: separai-vos, e separaram-se." (Minerva Brasiliense, n. 1, vol. III, 1844, p. 2)

De acordo com Lúcia M. B. Pereira das Neves e Guilherme Pereira das Neves em seu texto sobre o conceito de independência no escopo do "Léxico da História dos conceitos políticos do Brasil", a noção de independência pela qual estes homens da década de 1840 partilhavam estava quase que totalmente associada à uma ideia de liberdade relacionada à falta de sujeição ou autonomia. A noção de soberania ligada ao vocábulo, característica dos câmbios semânticos da modernidade, acabou ganhando sua tônica por volta da década de 1870 no Brasil (JUNIOR, 2014, p. 245249). Este empenho de separar o Brasil e Portugal também altera os significados dos vocábulos "pátria" e "nação", que dentro de um esforço político constituidor, formador de nacionalidade, oferece um novo aparato de sentido ao termo.

Para compreender com maior profundidade o cenário do qual buscamos compreender aqui torna-se necessário ater-se também às acepções dos vocábulos pátria e nação. De acordo com Marco Pamplona, que se dedicou ao estudo do termo "pátria" no mesmo livro citado acima, até o momento da independência, pátria era uma palavra utilizada para se referir ao local do Império Português o indivíduo pertencia, mas sua ressignificação se dá a partir dos marcos de fundação desta nova liberdade (JUNIOR, 2014, p. 281). A noção de pátria enquanto local de pertencimento ganha força a partir das conjurações que acometem a América portuguesa durante o século XVIII, mas são reforçadas através de uma intensa politização do termo a partir da revolução pernambucana de 1817, de acordo com o autor (JUNIOR, 2014, p. 284285).

Já nas Cortes Extraordinárias de 1822, o termo "pátria" ganhou destaque em relação a vocábulos que até então eram usados como sinônimos - como nação e reino. Durante o processo de independência e das regências no Brasil, nas décadas de 1820 e 1830, o termo pátria segue sofrendo alterações que acompanham a todas as transformações ocorridas durante modernidade, até desembocar em 1840 quando o termo se torna uma expressão do singular coletivo. Desta forma, conceito deixa de ter apenas o significado plural para adquirir também um significado singular, associado ao termo nação, ideia essa da qual compartilham os letrados de Minerva (JUNIOR, 2014, p. 297). 
Já o vocábulo "nação", também estudado por Pamplona, está associado, no século XVIII, à ideia de "região ou reino que vive debaixo do mesmo senhorio" (BLUTEAU, 1716 apud JUNIOR, 2014, p. 138). Ao longo do período avaliado por aqueles que dedicaram seus estudos sobre as alterações semânticas do léxico no mundo luso brasileiro, em meados do século XIX há a introdução da noção de povo no vocábulo "nação", já que seu significado se torna associado a concepção de "naturais de determinado país", enquanto povo tem como definição "todos os [seus] habitantes" (BLUTEAU, 1716 apud JUNIOR, 2014, p. 141). Nesta associação à ideia de povo, podemos demarcar que o povo faz parte da nação, é sua parcela mais numerosa. No entanto ela pertence aos cidadãos, ou seja, nação como está compreendida em 1858 no dicionário de Moraes e Silva, como apresenta Pamplona, não compete ao povo, mas aos "homens bons", aqueles que logram das responsabilidades políticas - sendo aptos a votarem ou serem eleitos (SILVA, 1858 apud JUNIOR, 2014, p. 142-143).

Em seguida, Ribeiro escreve "Pretendo só lançar uma vista de olhos na cultura intelectual do Brasil e dizer que a civilização atual é o resultado das ideias que presidem as suas grandes épocas históricas. " (Minerva Brasiliense, n. 1, vol. III, 1844, p. 2). Neste momento ele aponta que a introdução cristã e os livros como responsáveis pela propagação da cultura, que em conjunto com a circulação de notícias e ideias na Europa alimentou o espírito da literatura. A imprensa periódica aparece assim como elemento importante na construção de uma cultura intelectual, marcando a importância que acreditava obter a publicação na qual, a partir de então, estava à frente.

Ao tratar de Minerva, o autor proclama que caberia uma consideração sobre ela, mas que pelo fato de ainda existir, ele se concentraria nas mudanças que ocorreriam na publicação. Santiago Nunes Ribeiro anuncia:

\begin{abstract}
Até o presente, neste como em outros países, o máximo número dos leitores era o dos homens de letras, estudiosos, e as pessoas que sem o serem de profissão, haviam recebido uma educação literária. Hoje, porém, além destas que o tem em maior grau, o gosto da leitura se acha na parte sã de todas as classes, o singularmente nas duas mais úteis ao Estado, a dos negociantes e fazendeiros, pois que são como as artérias do corpo social nas quais gira a riqueza pública. Para estes, bem como para outros muitos leitores, a instrução deve ser mais recreativa que científica na forma, por que não leem, como os homens de profissão, para entender o que há de geral e abstrato, isto é, de filosófico nas ciências, ou nas particularidades, aquilo que por ser técnico só interessa a quem estuda ciência, ou exerce a arte. Isto posto, é sabido que o nosso fim é dar uma instrução sólida, substancial e divertida, os nossos leitores podem contar com artigos mais variados e recreativos que os da Minerva do ano findo, sem que porém se entenda que esta publicação vai descer tanto que se nivele a alguns Magazines, ou armazéns de notícias e descrições nimiamente superficiais e populares. (Minerva Brasiliense, n. 1, vol. III, 1844, p. 2)
\end{abstract}

Este é o manifesto do novo redator. A mudança seria agora para ilustrar outra camada da elite imperial, não mais apenas a intelectual a fim de assegurar a independência cultural do país, mas sim a econômica, com o intuito de homogeneizar as elites. Para isto, fica decidido que nesta nova fase da Minerva serão diminuídas as quantidades de poesia para dar lugar a "escritos de mais positiva utilidade." (Minerva 
Brasiliense, n. 1, vol. III, 1844, p. 3). Depois disso, Santiago Nunes anuncia a mudança mais clara deste novo momento:

\begin{abstract}
Resta-nos falar de uma mudança que julgamos utilíssima na marcha da publicação e na matéria desta última. Observando a escassez de algumas obras e o preço exorbitante delas, entendemos conveniente dar em 12 números alternados de Minerva reimpressões das ditas obras de novelas, viagens, ou quaisquer outras que preencham nossos fins. Todas quantas pessoas temos consultado sobre esta ideia de um de nossos colegas mais ilustrados e zelosos, Ihe dão assenso e louvor sem restrição. Resulta disso que os nossos assinantes terão 340 réis um volume de 56 páginas que se vendem de $1 \$ 000$ a $2 \$ 000$ nas livrarias. (Minerva Brasiliense, n. 1, vol. III, 1844, p. 3)
\end{abstract}

Santiago Nunes Ribeiro nomeou a referida coleção de "Biblioteca Brasílica", afirmando em seu artigo/introdução que "o povo não pode exercer seus direitos constitucionais, se vive na ignorância. Só o instruído estará capacitado de governarse." (LOPES, 1978, p. 37). Remetendo ao conceito de boa sociedade, como composta por votantes e eleitores (MATTOS, 2009. p. 27) e também como sendo a reduzida elite econômica, política e cultural do império (NEVES, 2008. pp. 95-97), percebe-se que a nova proposta de Ribeiro é direcionada, portanto, a este estrato social, uma vez que ele apresenta para a pequena camada da população que possui direitos constitucionais.

Prosseguindo com o artigo, Nunes Ribeiro afirma que Francisco de Salles Torres Homem deixou a chefia de redação da publicação definitivamente, mas que ainda esperam tê-lo como colaborador das publicações, fato que se concretiza. Depois de apresentar considerações sobre a arte deste primeiro número, que não foi realizada pelo artista combinado, encerra-se a apresentação desta nova fase com a enumeração de cada contribuinte da publicação, separados pela respectiva seção, e um breve texto sobre a "Abertura do Atheneo", também de Santiago Nunes Ribeiro.

A partir da compreensão de para quem se destinava Torres Homem em sua introdução, podemos destacar que o novo redator da revista não foge muito da regra, no entanto busca alargar seu público através da proposta de uma leitura mais recreativa. Sendo assim, é perceptível que a grande massa não está inclusa nestes planos, bem como quando Santiago Nunes realiza uma repaginação na estrutura do periódico a fim de também incluir a classe econômica mais expressiva do país: os fazendeiros e negociantes.

\title{
Autores e artigos que discutem projetos ilustrativos em Minerva
}

Ao longo da revista é possível também observar outros artigos que reafirmam esta proposta. A partir daqui, mais voltada para a questão literária, pode-se destacar que três artigos nos oferecem um campo de percepção acerca da questão pedagógica, que é tão forte na revista e na imprensa do oitocentos de forma geral. São artigos 
como "Bibliografia: obras sobre geografia e história do Brasil - o compêndio do Sr. General Abreu e Lima”, assinado por T. e publicado no segundo número da primeira fase da revista, "Parnaso Brasileiro", produzido por Santiago Nunes Ribeiro e também publicado no mesmo número e, por fim, "Utilidade e vantagens das ciências e letras", escrito por Dr. Lapa e publicado no $5^{\circ}$ número deste periódico que nos permitem observar como este projeto se faz presente no seu corpo de publicações.

O primeiro texto destacado trata de uma obra produzida pelo General Abreu e Lima e foca na geografia e história do Brasil. T., portanto, destaca em seu artigo a importância de obras deste tipo para a nação. Ao iniciar o texto o autor afirma que o Brasil é mais comumente conhecido pelos estrangeiros do que pelos próprios brasileiros, já que seriam eles quem publicavam estudos sobre o país - como os exemplos que T. ressalta sobre o tamanho de suas montanhas ou a extensão de seus rios. Ao fechar a ideia, o autor afirma que o conhecimento sobre a nação é praticamente ignorada por sua população, a não ser por questões locais ou de interesses econômicos sobre algum lugar. Nesse sentido, afirma:

\begin{abstract}
Estranhas umas as outras, falta as nossas províncias a força do laço moral, o nexo da nacionalidade espontânea que poderia prender estreitamente os habitantes desta imensa peça, que a natureza abarcou com os dois maiores rios do universo. A história do país ou depositada em antigos e fastidiosos volumes e geralmente ignorada, ou escrita até certo tempo por mãos menos aptas, por estrangeiros que, como Beachamp, trataram só de compor um romance, que excitasse a curiosidade de seus leitores na Europa, não pôde despertar no espírito de nossa juventude o nobre sentimento de amor de pátria, que torna o cidadão capaz dos maiores sacrifícios, e o eleva acima dos cálculos mesquinhos do interesse individual. (Minerva Brasiliense, n. 2, vol. I, 1843, p. 51)
\end{abstract}

A partir de Hobsbawn podemos perceber que não são as nações que formam os Estados e os nacionalismos e sim o contrário; são os Estados que formam as nações e seus nacionalismos (HOBSBAWN, 2013. p. 19). Para os teóricos do começo do século XIX, a nação se estabelecia a partir da etnicidade, idioma, religião, território e lembranças históricas comuns. Para, além disso, a construção da ideia de nação e seus nacionalismos é uma tarefa das elites, que se vestem dos motivos nacionais, para construírem uma narrativa histórica a fim de unificar o povo através de uma ideologia comum e isso pode ser observado em Minerva (HOBSBAWN, 2013, Passim). De acordo com Pamplona, nos léxicos de Antonio Morais Silva e do padre Raphael Bluteau, na década de 30 do oitocentos, buscam definir o que é nacional a partir também da definição do que é o estrangeiro, numa clara tentativa de definição através da alteridade. De acordo com o autor, ambos os dicionários descrevem o termo nação relacionando-o ao termo civitas, descrevendo que o nacional tem a ver com gente de um país ou região, que compartilha o mesmo idioma, legislação e governo (JUNIOR, 2014, p. 139).

Pamplona apresenta um trecho do dicionário de Morais e Silva de 1858, no qual o verbete nação está associado ao vocábulo de povo, que se definia da seguinte forma:

Revista História em Reflexão, Vol. 15, N. 29 | jan. a jun. de 2021 
(...) A palavra nação indica uma relação comum de nascimento, de origem; povo uma relação de número, de reunião. A nação consiste nos descendentes de um mesmo pai, e o povo na multidão de homens reunidos em um mesmo sitio. Em outra acepção a palavra nação compreende os naturais do país; e o povo seus habitantes. Um povo estrangeiro que forma uma colônia em país longínquo, continua ainda a ser Inglês, Português, Espanhol, etc. é-o por nação, ou de origem. Diversos povos reunidos, ligados por diferentes relações comuns em um mesmo país, formam uma nação; e uma nação se divide em vários povos, diversos uns aos outros por diferenças locais e físicas, ou políticas e morais. A nação está intimamente unida ao país pela cultura, ela o possui; o povo está no país, ele o habita. (...) (SILVA, 1858 apud JUNIOR, 2014, p. 140.)

Nesse sentido, o autor destaca uma questão importante para eles, que apresenta também uma das marcas mais fortes do periódico, bem como sua pretensão ilustrativa e pedagógica, quando pergunta "Como legislar convenientemente para um país que não se conhece bem? Como dispor de matéria, sobre a qual se possui apenas uma notícia leve, geral e muito imperfeita?" (Minerva Brasiliense, n. 2, vol. I, 1843, p. 51). Desta forma, além de deixar bastante evidente uma das maiores preocupações desta publicação, ele ainda apresenta a quem se dirige: aos futuros possíveis legisladores deste jovem país. Ao continuar desenvolvendo sua ideia de que sem conhecer o próprio território tudo neste país é afetado, ele apresenta sugestões, como por exemplo, usar os mapas já existentes para exame e correção, litografar e distribuir ao público por preços módicos, o que reafirma a proposta de oferecer ilustração para seu público leitor (Minerva Brasiliense, n. 2, vol. I, 1843, p. 51).

Sobre a questão da história do Brasil, T. afirma que o general adota com destreza os métodos de pesquisa, afirmando que trata os assuntos com a imparcialidade desejada inclusive dos eventos aos quais fora testemunha. O "amor pela verdade" é um dos elementos destacados no que tange a confiabilidade do estudo realizado pelo General. O compêndio ao qual a crítica se refere trata dos eventos ocorridos da Independência do país até a coroação de D. Pedro II e, de acordo com o autor deste artigo, mesmo que lhe falte uma exatidão no tratamento dos fatos, ao menos ele é rico em documentos precisos (Minerva Brasiliense, n. 2, vol. I, 1843, p. 52). Importante lembrar que, como destaca Valdei Lopes de Araújo (ARAÚJO, 2008), esta é uma preocupação inicial do Instituto Histórico e Geográfico Brasileiro: como se deve escrever a História nacional, antes de ser escrita de fato. Portanto, o rigor das fontes é uma preocupação prévia destes homens das letras. Ao final o autor conclui que uma história completa do Brasil de fato ainda resta compor e entrega esta missão ao recémfundado IHGB, que seria realizada parcialmente em 1845 pelo alemão Carl Friedrich Philipp von Martius, que desenvolveu métodos necessários a serem empregados, sendo completada a partir de 1854 com a publicação de "História Geral do Brasil" de Francisco Adolfo Varnhagen (Minerva Brasiliense, n. 2, vol. I, 1843, p. 52-53).

Sobre a relação do passado para a construção nacional apresenta-se a relevância de evocar Ernest Renan, um letrado contemporâneo aos processos de construção dos nacionalismos, e também defensor deles, em seu texto sobre o qual se propõe analisar a nacionalidade. Em "O que é nação", o autor defende que "A 
nação moderna é, portanto, um resultado histórico produzido por uma série de fatos que convergem para um mesmo ponto" (ROUANET, 1997, p. 20), eis a importância da história neste processo. Neste sentido, a importância do conhecimento de seu passado, de acordo com Renan, é muito semelhante ao apresentado por T., uma vez que é um dos elementos primordiais para promover o nexo de nacionalidade evocado pelo autor da revista. Renan afirma:

A nação, como o indivíduo, é o resultado de um longo passado de esforços, de sacrifícios e de devoções. O culto dos ancestrais é, entre todos, o mais legítimo; os ancestrais fizeram de nós o que nós somos. Um passado heroico, grandes homens, glória (refiro-me a verdadeira), eis o capital social sobre o qual assenta-se uma ideia nacional. Ter glórias comuns no passado, uma vontade comum no presente; ter feito grandes coisas juntos, querer continuar a fazê-las, eis as condições essenciais para ser um povo (ROUANET, 1997. p. 39).

De acordo com o trecho é possível ver uma defesa sobre a importância da história e da memória sobre o passado de um povo no processo de construção da nacionalidade. Na defesa ao culto dos ancestrais, da importância deles para os indivíduos no presente - metaforizados também como nação - e de um passado heroico que una uma grande massa de pessoas também traz a tona uma proposta de operar no campo das ideias esta união. Neste sentido podemos compreender que quando os homens letrados que atuavam em Minerva se preocupavam com as glórias do passado comum, o que desejam é suscitar a vontade comum do presente de seguir em constante progresso rumo a se tornar uma nação civilizada.

Em "Parnaso Brasileiro", escrito por Santiago Nunes Ribeiro, há um direcionamento para a questão literária nacional por tratar-se de uma crítica ao livro escrito que tem por título o mesmo do artigo, que foi escrito pelo Sr. Dr. Pereira da Silva. O autor inicia seu texto tratando da importância de livros e sobre o alto custo deles e ressalta, demonstrando mais uma vez a preocupação pedagógica e ilustrativa que direciona o projeto desta publicação:

A livraria de um país ilustrado deve procurar os meios de satisfazer a exigência de bons livros, desejados pelos amadores de sã e amena instrução, e isto pelo preço mais módico (...) Cumpre pois descobrir os meios de imprimir e vender livros recreativos e morais, por preço cômodo. (Minerva Brasiliense, n. 2, vol. I, 1843, p. 53)

Ao prosseguir, Santiago Nunes apresenta a relevância de uma imprensa ilustrativa ativa, para além da periódica. Ou, sendo periódica, que fosse literária e científica, tal qual é a publicação objeto deste texto, como afirma ao dizer que "(...) se a imprensa não periódica (ou periódica, mas literária e científica), tivesse sido mais ativa; a instrução pública teria ganhado muito. " (Minerva Brasiliense, n. 2, vol. I, 1843, p. 53). Esta foi uma reflexão, de acordo com Nunes Ribeiro, que não se aplica ao livro em questão, uma vez que ele é uma compilação de produções das belas letras brasileiras.

Já no artigo de Dr. Lapa, "utilidade e vantagens das ciências e letras", publicado no número 5 da revista, revela uma sumária crença no progresso e na perfectibilidade 
do homem através do conhecimento e desenvolvimento crescente dele, tal como pudemos observar no editorial da primeira fase da revista escrito por Torres Homem. No artigo em questão o autor afirma que o estudo das ciências e das letras seria uma forma de ampliar o domínio da existência e consequentemente promoveria a felicidade e o progresso do homem civilizado, por isso a importância dele. Seria através destes estudos que o espírito humano se elevaria e a sociedade como um todo lucraria com suas vantagens em decorrência disso (Minerva Brasiliense, n. 5, vol. I, 1844, p. 135).

Como o foco deste trabalho centra-se na questão literária da revista, portanto não há necessidade de se deter aos detalhes que o autor expressa na defesa da importância do estudo das ciências e sim, das letras. Inicialmente é importante destacar que Dr. Lapa considera, conforme se expressa em seu texto, que a cultura das letras - por ele descrita como a poesia, a música, a história e a eloquência são menos importantes que as ciências em termos de utilidade. À cultura das letras o autor designa uma relevância recreativa, uma forma útil de se obter prazeres de espírito, descanso e aperfeiçoamento (Minerva Brasiliense, n. 5, vol. I, 1844, p. 136). Neste sentido, Dr. Lapa escreve que "As letras formam o coração e o espírito; elas ensinam como conhecer e apreciar os encantos e doçuras da virtude; fonte fecunda são de prazeres puros para o homem; e para quem for dotado de certa elevação de espírito, nenhum gosto corre parelhas com o que ele sente em sua cultura. " (Minerva Brasiliense, n. 5, vol. I, 1844, p. 136).

Embora atribua menos importância às letras, não se pode deixar de notar que existe sim uma importância em sua produção já que promoveria instrução mesmo em momentos de lazer. É neste ponto que o artigo revela sua importância, uma vez que levanta formas de tornar a população de seu país mais instruída a fim de civilizá-la, o que entra em consonância com todo o projeto pedagógico deste periódico. Neste sentido, ratificando o que foi posto, o autor ainda afirma que:

Em todos os países e em todas as épocas da vida as letras recreiam e
descansam agradavelmente o espírito do homem; instruem e formam a
mocidade; deleitam e aformosentam a vida na velhice; abrilhantam e servem
de ornamento na prosperidade, consolam na desgraça, e são asilo seguro
contra as dores pungentes da alma; no interior de nossas casas são nossas
delícias, em nenhuma situação da vida nos importunam, ainda no exercício
dos misteres domésticos, e perenemente velam conosco em viagem, ou já
no campo. (...) São finalmente as letras que, desde Hesíodo e Homero, hão
dado origem a tantas obras primas do espírito humano; obras imortais, que
serão em todo o sempre objeto das delícias e da constante admiração dos
homens de gosto puro e iluminado. (Minerva Brasiliense, n. 5 , vol. I, 1844, p.
136-137)

Ainda dentro desta questão pedagógica tão latente em Minerva, pode-se destacar os artigos de Emile Adet sobre literatura contemporânea francesa. Esta é uma série de artigos publicados em três números da revista que tem como propósito avaliar a produção literária francesa contemporânea, mas que nos permite enxergar também reafirmações das propostas civilizadora, pedagógica e ilustrativa. No primeiro deles, publicado no segundo número de Minerva, o autor apresenta ideias como a França ser a provedora de civilização na contemporaneidade, o Brasil como sendo discípulo dela na literatura da época presente e qualifica a literatura contemporânea 
francesa como sendo a nova escola literária - chamada por ele de lirismo (Minerva Brasiliense, n. 2, vol. I, 1843, p. 37).

A partir de então, neste número, Emile Adet realiza uma revisão da literatura francesa passada, a fim de encontrar qual seria o ponto de separação da antiga para a nova escola. Atribui, por fim, essa ruptura às revoluções que sacudiram a França afirmando ela estaria recuperando o caráter nacional de sua literatura. Elege Victor Hugo como o mais brilhante e nobre representante desta nova escola moderna de literatura, à qual ressalta não estar ainda fixa e não contar com numerosos representantes. (Minerva Brasiliense, n. 2, vol. I, 1843, p. 40-41)

No artigo seguinte, no número três desta revista, Adet define a poesia lírica como sendo ode e elegia, da qual diz que não irá separar. Afirma que o primeiro autor deste lirismo é Chateaubriand, que revelou o estilo e permitiu que outros autores pudessem criar a partir dele, e defende originar-se "de uma faísca saído do mesmo foco poético" (Minerva Brasiliense, n. 3, vol. I, 1843, p. 89). Adet então complementa afirmando que Lamartine e Victor Hugo são discípulos de Chateaubriand, contudo exalta a performance do segundo dizendo "que o vento lançou[-o] em novos caminhos para fazê-lo percorrer espaços até aí desconhecidos. " (Minerva Brasiliense, n. 3, vol. I, 1843, p. 89). Por fim, trata de Béranger, que, posto entre Lamartine e Victor Hugo, é descrito como "uma das glórias mais populares do século, o poeta mais nacional da França." (Minerva Brasiliense, n. 3, vol. I, 1843, p. 91). Partindo destas informações, podemos perceber que o lirismo da literatura francesa nada mais é do que o movimento romântico, escola literária desenvolvida pelos autores de Minerva.

Já no terceiro e último artigo sobre este tema, Emile Adet defende a ideia de que apenas a França possuía uma grande literatura. No desenvolvimento desta ideia o autor ressalta, a fim de apresentar que a escola contemporânea apenas está em seu início:

\begin{abstract}
A literatura moderna, cuja restauração só começou em 1819 a lançar os primeiros clarões, e que em 1828 já havia derramado extensa luz, não é folha nem do século 18 , nem do 19 , ela nasceu do coração do primeiro cristão. O que caracteriza a literatura contemporânea da França é a poesia épica, que se revelou a Chateabriand, Alfredo de Vigny, Alexandre Soumet e Edgar Quinet; a poesia lírica, isto é, a ode que se revelou a Victor Hugo; a elegia, a Lamartine. O romance, que tomou novas feições; que toca hoje em todas as questões sociais e não se acha mais comprimido no estreito círculo que outrora não pôde alargar. A filosofia, que sob a influencia do restabelecimento literário e do espiritualismo alemão, deu um passo para a verdade. A história, que ora entrou nos limites da filosofia e ultrapassou os limites que punham travas a sua marcha. A linguística, que, entregue as sábias mãos de Chezi, dos Jaubert, dos Quatremère, dos Saint-Martin, dos Abel Remusat, dos Sylvestre de Sacy, dos Balbi, dos Bernouf, subiu ao ponto que elevaram em Alemanha os Bopp, os Eichhorn, os Hammer, , os Ticksen, os Vater, os Klaproth, os Adelung, os Eischoff e os Humboldt. Há em todos os espíritos um despertar geral, uma atividade incessante para o progresso; mas também uma inquietação sobre o futuro, a incerteza entre o presente, em tudo a dúvida e uma vontade fraca e vacilante. A literatura não tem ponto central ao qual tudo convirja; eis a causa destas apalpadelas contínuas, deste andar ao acaso, desta liberdade que se torna desordem: casa qual abre um caminho sobre qual forma um sistema (Minerva Brasiliense, n. 4, vol. I, 1843, p. 110).
\end{abstract}


$\mathrm{E}$, embora negue que o Brasil tenha conseguido alcançar o mesmo estágio de desenvolvimento literário que a França, ainda sim ele apresenta sua defesa ao romantismo:

\begin{abstract}
Digamo-lo, posto que não querendo constituir-nos defensores do romantismo, é uma injustiça que se faz à escola moderna compará-la à antiga. Quanto a esta, os tempos passaram; aquela apenas começa o seu período. Aguardai, não compareis por ora; há quiçá um gênio próximo a nascer da sombra! Newton aparece no mesmo ano em que morre Galileu, Shakespeare só havia quatro anos que tinha falecido quando Molière veio ao mundo, e quando o gênio de Voltaire se extinguia, o fogo celeste já abrasava a fronte de um menino ignorado em uma ilha! Para que apareça a aurora é forçoso o crepúsculo. (Minerva Brasiliense, n. 4, vol. I, 1843, p. 110-111)
\end{abstract}

Muitas são as ideias que estes textos direcionam no que se refere ao projeto do periódico em si. Inicialmente, podemos ressaltar a importância dada à França como provedora de civilidade e progresso pelos quais devem ser buscados como exemplo pela jovem nação. Adet apresenta seu profícuo conhecimento sobre a literatura francesa e busca fornecê-lo ao seu leitor a fim de que este também compreenda os processos pelos quais a literatura passou, bem como seus processos históricos.

De acordo com Ricupero, "Sua influência não é, porém, mero modismo, já que o meio intelectual latino-americano e o francês enfrentam ordem de problemas em certo ponto similar" (RICUPERO, 2004. p. 45). Ao tratar da literatura como um meio de recuperar a nacionalidade deste país europeu após ser abalado por duas revoluções, é possível interpretar que este gênero literário tão aclamado por Emile Adet seria capaz de promover a nacionalidade pelos quais buscam os autores deste impresso, tendo em vista que pode-se compreender o movimento romântico brasileiro como o responsável por pensar, mesmo que de forma imatura, quais seriam os códigos e elementos que constituem a literatura de nacionalidade brasileira. Neste sentido, compreender o romantismo francês seria uma forma de tornar o romantismo brasileiro possível e aclamado pela sua população.

\title{
O papel da história e da literatura no projeto ilustrativo de Minerva
}

$\mathrm{Na}$ avaliação das transformações e projetos encabeçados pela elite imperial a fim de se desenvolver um imaginário nacional que fosse capaz de unir a população brasileira em uma nação coesa, grande parte dos autores concorda em afirmar que história e literatura protagonizam o intento. Sua realização se dá com certo sucesso ao pensarmos que o projeto nacional hegemônico - o mesmo que pertence à elite letrada brasileira - sai vitorioso na construção de um Brasil excludente, que traz as marcas da escravidão até os dias atuais. João Paulo G. Pimenta e Valdei Lopes de Araújo, no livro sobre o léxico dos conceitos políticos no Brasil, são os que se dedicam ao estudo e análise do conceito de história no projeto do léxico político brasileiro afirmam isso ao longo de seu texto. 
A partir dos autores é possível observar que no século XVIII o verbete história refletia o tipo de historiografia produzida pelas instituições portuguesas, carregadas da ênfase da retórica ciceroniana de história mestra da vida. Já no final deste mesmo século, com o mundo luso brasileiro abalado pelas conjurações emancipacionistas, a história começa a desempenhar a função de campo de experiência comum, que os autores denominam como "narrativas ilustradas", os quais chamam atenção para os poemas O Uraguay e Vila Rica, de José Basílio da Gama e Claudio Manoel da Costa. Contudo é apenas a edição de 1870 de Morais Silva que aponta para uma definição de história que separa o historiador do cronista e endossa o verbete com seu sentido moderno de evolução e progresso, caracterizando mais uma vez o movimento indicado por Koselleck da criação de singulares coletivos da modernidade (JUNIOR, 2014, p. 103-108).

Os autores chamam especial atenção para estes movimentos do final do século XVIII, os quais afirmam oferecer uma nova concepção de futuro e inaugurando também um novo sentido de história. Numa segunda ruptura destacada por Lopes e Pimenta, a transferência da capital metropolitana de Lisboa para o Rio de Janeiro, alarga a concepção de presente, que se consolida como campo transitório para um futuro do qual se procurava antever. A abdicação de D. Pedro I, na década de 1830, também causa alteração nas ideias e a necessidade de construção de uma história nacional como formação de um campo de experiência da nacionalidade. É neste cenário que história e literatura assumem a dianteira na formação da narratividade dos projetos de nação encabeçados pela elite imperial brasileira (JUNIOR, 2014, p. 109-115).

Desta forma, redescobrir o passado, revisitar a história e literatura colonial e se voltar às letras a fim de organizar a produção intelectual da colônia, que foi marcada pelo sufocamento metropolitano, passou a ser a tarefa dos homens de letras deste período. A partir do que foi apresentado neste texto é possível perceber que os redatores de Minerva se dedicavam a esta árdua tarefa. A literatura foi, portanto, transformada em processo de desenvolvimento da identidade nacional, deixando a noção de história como sucessão de fatos isolados de lado. Dentro deste debate no qual a história ganhou uma carga política muito intensa, o Instituto Histórico e Geográfico Brasileiro foi criado em 1838, já que o projeto de história da literatura do romantismo brasileiro não correspondia a uma escrita da história nacional (JUNIOR, 2014, p. 115-116).

Neste sentido, o IHGB se consolida como local de produção institucional de história. Neste espaço foi possível debater quais seriam as bases da história nacional ideal a partir deste novo campo de experiências moderno. A independência se caracterizou como fio condutor dos debates acerca da narrativa de nação que seria adotada, já que teria produzido as condições de sua escrita, como afirmam Lopes e Pimenta. Ou seja, de acordo com os autores, a independência do Brasil foi o evento que possibilitou a produção escrita sobre a nacionalidade, o que significa que a história do Brasil dos românticos do oitocentos se tornou a história de seu processo emancipatório (JUNIOR, 2014, p. 116-117).

Chamo atenção para o alinhamento ideológico e intelectual dos homens 
que publicavam em Minerva acerca do projeto acima destacado, que em parte foi constatado neste artigo. A urgência ilustrativa que foi demonstrada por seus redatoreschefes nos editoriais da revista e ratificada pelo corpo de publicações na revista se apresenta como confirmação deste projeto. Minerva Brasiliense se consolida, portanto, como espaço não institucional onde os debates sobre as narrativas nacionais são desenvolvidos.

O que podemos perceber a partir do que foi visto é como a alteração de conceitos a partir dos preceitos da modernidade, que teve como marco de transformação a Revolução Francesa, todo um projeto de ordenação da jovem nação foi montado, buscando desenvolver este país à luz da história e filosofia europeia. A literatura e a história, responsáveis por carregar as marcas das ações nos homens no mundo, eram duas das engrenagens desta proposta, mas que muitas vezes - por motivo da fluidez das suas concepções no mundo do oitocentos - se fundiam numa só. Os autores que publicavam neste periódico mostraram-se alinhados a este projeto, que acaba sendo o fio condutor das publicações de seus colaboradores.

\section{REFERÊNCIAS}

Diário do Rio de Janeiro. "Prospecto". Ano 23, número 214, 26 de setembro de 1843. Disponível on-line em: http://memoria.bn.br/DocReader/DocReader. aspx?bib=094170 01

HOBSBAWN, Eric J. Nações e nacionalismos desde 1780: programa, mito e realidade. Rio de Janeiro: Paz e Terra, 2013.

JUNIOR, João Feres (Org.). Léxico da história dos conceitos políticos do Brasil. Belo Horizonte: Editora da UFMG, 2014.

KOSELLECK, Reinhart. "Uma história dos conceitos: problemas teóricos e práticos". In: Estudos Históricos. Rio de Janeiro, vol. 5, n¹0, 1992, pp. 134-146.

KOSELLECK, Reinhart. Futuro passado. Para uma semântica dos tempos históricos. Rio de Janeiro: Contraponto; Ed. PUC-Rio, 2006.

LOPES, Hélio. A divisão das águas: contribuição ao estudo das revistas românticas Minerva Brasiliense (1843-1845) e Guanabara (1849-1856). São Paulo: Secretaria da cultura, ciência e tecnologia, 1978.

MATTOS, Ilmar Rohloff de. "O gigante e o espelho". In: O Brasil Imperial - Vol. II 1831-1889. Rio de Janeiro: Civilização Brasileira, 2009.

Minerva Brasiliense. Rio de Janeiro. 31 edições, 1843-1845. - Disponível on-line em: http://hemerotecadigital.bn.br/acervo-digital/nitheroy/700045 
NEVES, L. M. B. P. das; GUIMARÃES, L. M. P. (Orgs). Minerva Brasiliense: Leituras. Rio de Janeiro: Contra Capa, 2016.

RICUPERO, Bernardo. O Romantismo e a ideia de Nação no Brasil (1830 - 1870). São Paulo: Martins Fontes, 2004.

ROUANET, Maria Helena (Org). Nacionalidade em Questão. Rio de Janeiro: Universidade do Estado do Rio de Janeiro, 1997.

Eternamente em Berço Esplêndido: a fundação de uma literatura nacional. São Paulo: Siciliano, 1991.

Recebido em fevereiro de 2018.

Aprovado para publicação em fevereiro de 2021. 